\title{
"Whose bowel is it anyway?" A case study illustrating the practical difficulties resulting from a childhood procedure that impinges upon an adult with spina bifida attempting to live independently Lissa Wright
}

Address: Princess Royal Spinal Injuries Centre, Osborn Building, Northern General Hospital NHS Trust, Herries Road, Sheffield, S5 7AU, South Yorkshire, UK

Email: Lissa Wright - lissa.wright@sth.nhs.uk

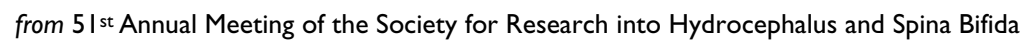
Heidelberg, Germany. 27-30 June 2007

Published: 20 December 2007

Cerebrospinal Fluid Research 2007, 4(SuppI I):SI6 doi:I0.II86/I743-8454-4-SI-SI6

This abstract is available from: http://www.cerebrospinalfluidresearch.com/content/4/SI/SI6

(c) 2007 Wright; licensee BioMed Central Ltd.

\section{Background}

John is 23 years old, has spina bifida, shunted hydrocephalus and left hemiparesis. John had caecostomy with insertion of a gastrostomy button 10 years ago for the purpose of antegrade colonic enema (ACE) bowel management. The bowel washouts caused severe abdominal discomfort and were ineffective. The button was therefore replaced by a jejunostomy feeding tube, which delivered the fluid into the mid transverse colon making him continent with a regime of washouts every third day. After attending college for several years, John moved to live alone in a flat, away from his very supportive parents. John's physical disabilities prevented him from completely managing his bowel irrigation independently. Community nurses have insufficient resources to assist John without detracting from his limited social life. Care staff are willing but not allowed to assist.

\section{Materials and methods}

Interviews with John and his parents: Telephone interviews with community nurses and social care agencies.

\section{Results}

Following lengthy discussion between all parties, a satisfactory solution was reached. John changed the method of funding his social care in order to create a contract with his social carers allowing him greater flexibility to meet his needs.
The procedure was reduced to its component parts. John performed the elements of which he was physically capable, leaving his social carers to undertake the remainder. District nurses undertook risk assessments to ensure that the procedure was carried out with no breech to John's safety and wellbeing.

\section{Conclusion}

Childhood procedures may have implications for management in adulthood and in the ever-changing health and social care climate consideration must be given to the long-term needs and abilities of the client. 